\title{
DOUBLE MATING OF RABBITS TO DETERMINE CAPACITATION TIME
}

\author{
P. J. DZIUK \\ Animal Science Department, University of Illinois, \\ Urbana, Illinois, U.S.A.
}

(Received 27th March 1965)

\begin{abstract}
Summary. Thirty-eight does were double mated to two bucks whose offspring were distinguishable from each other. The interval between mating to the first buck and mating to the second buck was $\frac{1}{2}, 1$ or $2 \mathrm{hr}$. The first buck was mated $10,9,8,7,6,5$ or $4 \mathrm{hr}$ before ovulation. The first buck sired $86 \%$ of the offspring when the interval between bucks was $2 \mathrm{hr}$. When the interval between males was shortened, the first male sired the majority of offspring but the proportion was less than that after a 2-hr interval. It was concluded that spermatozoa that have resided in the genital tract of the doe have a competitive advantage over other spermatozoa that have spent less time in the female. The advantage did not disappear after the $6 \mathrm{hr}$ residence, usually thought to be adequate for capacitation, but extended to at least $10 \mathrm{hr}$. Capacitation (maturation) may possibly be a quantitative phenomenon as well as a qualitative one.
\end{abstract}

\section{INTRODUGTION}

Capacitation of rabbit spermatozoa has been shown to take about $6 \mathrm{hr}$ (Austin, 1951; Chang, 1951; Noyes, Walton \& Adams, 1958; Adams \& Chang, 1962b). The determination of this time has either required in-vitro manipulation of spermatozoa or been based on an estimate of the post-ovulatory life of the unfertilized rabbit egg. A truer estimate might be obtained if these two limitations could be avoided.

It was hypothesized that by mating a doe with one buck at a certain time before ovulation and then to a second buck whose offspring were distinguishable, an hour or two later, that the offspring should be only from the first buck when the interval from the second mating to ovulation was shorter than capacitation time. If both matings occurred at intervals greater than capacitation time then litters of mixed parentage might result. The following report is an account of experiments designed to test this hypothesis.

\section{MATERIALS AND METHODS}

A homozygous checkered giant buck served as the genetically dominant black (B) male and a homozygous New Zealand buck served as the recessive white (W) male. Single matings to non-experimental does were made periodically before, during and after the experimental matings to verify homozygosity 
and to determine fertility. Several different vasectomized bucks were used. Thirty-eight experimental litters from twenty-four homozygous $\mathrm{W}$ females were observed for eye and skin colour within $12 \mathrm{hr}$ of birth and again several days later.

To induce ovulation, does were mated to vasectomized males twice within as short a span of time as possible, usually within $30 \mathrm{sec}$. Immediately afterwards they were injected intravenously with 50 to 100 i.u. of human chorionic gonadotrophin (The Upjohn Company) to ensure that ovulation occurred $10 \mathrm{hr}$ later. The first mating to a fertile buck took place either $10,9,8,7,6,5$

TABLE 1

NUMBER AND COLOUR OF OFFSPRING AFTER DOUBLE MATING AT A 2-HR INTERVAL

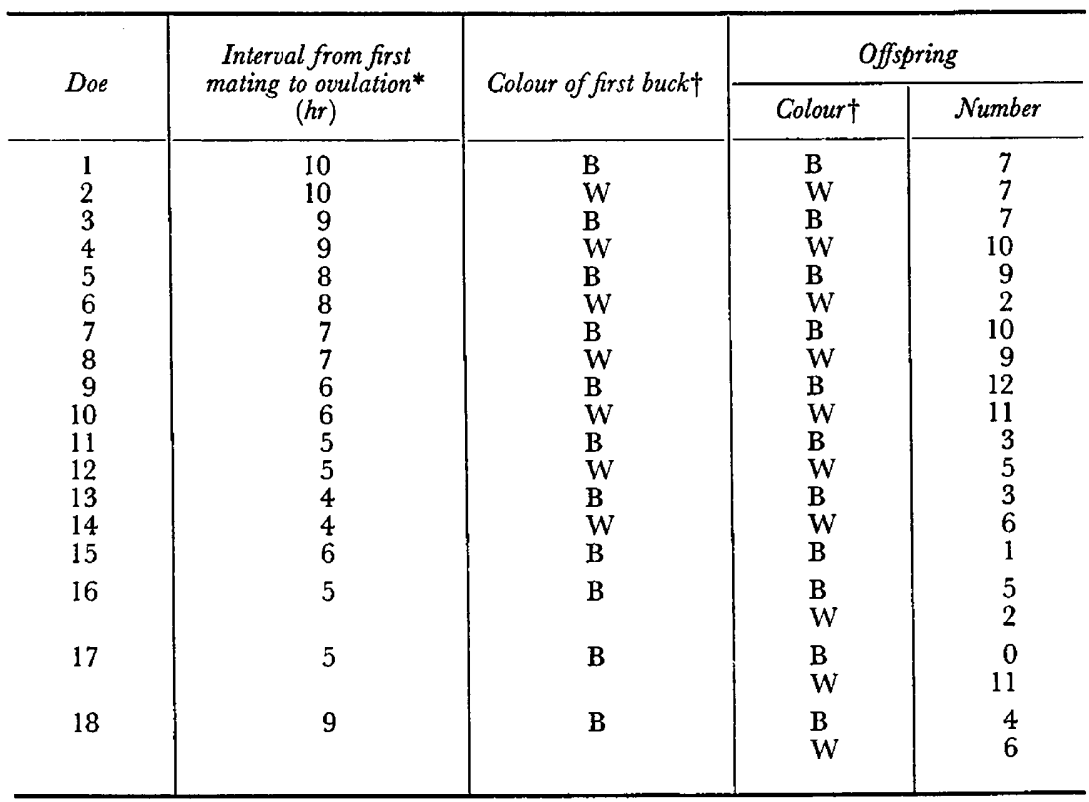

* Second male mated $2 \mathrm{hr}$ later and is of the opposite colour.

$\uparrow \mathrm{B}$ is black; $\mathrm{W}$ is white.

or $4 \mathrm{hr}$ before ovulation and the second mating $\frac{1}{2}, 1 \mathrm{or} 2 \mathrm{hr}$ afterwards (Tables 1 and 2). The bucks were used alternately as the first male. Each doe was mated twice to each of the bucks to reduce the likelihood that limiting numbers of spermatozoa from a single mating by either buck could be responsible for differences in ratios of offspring. The matings to the same buck were made within as short a time span as possible, usually less than $30 \mathrm{sec}$. In one experiment seven does were induced to ovulate as usual and were then mated to a second vasectomized buck at 10, 9, 8, 7 or $6 \mathrm{hr}$ before ovulation. Either 1 or 2 hr later they were mated to one of the two fertile bucks.

\section{RESULTS}

Results of double-matings, except four which produced no litters, are shown in Tables 1 and 2. As shown by does numbered 1 to 18 , the first buck sired $86 \%$ 
of the offspring when the interval between bucks was $2 \mathrm{hr}$. The B buck sired the smaller proportion of offspring when used in direct competition (does 19 and 20, Table 2) and he did not sire all the offspring when used first (does 16, 17,18 , Table 1). He could apparently overcome this disadvantage in most cases if he were used $2 \mathrm{hr}$ before the $\mathrm{W}$ buck. The B buck could apparently not overcome this disadvantage if he were used only $\frac{1}{2}$ or $1 \mathrm{hr}$ ahead of the W buck, especially when the mating-to-ovulation interval was $8 \mathrm{hr}$ or less (does $27,28,29,30,31$, Table 2). It may be construed that because the B buck had no offspring from does $27,28,29,30$ or 31 , that he was sterile during the period

TABLE 2

NUMBER AND COLOUR OF OFFSPRING AFTER DOUBLE MATING AT LESS THAN A 2-HR INTERVAL.

\begin{tabular}{|c|c|c|c|c|c|}
\hline \multirow[b]{2}{*}{ Doe } & \multicolumn{2}{|c|}{$\begin{array}{l}\text { Interval from } \\
\text { mating to ovulation (hr) }\end{array}$} & \multirow[t]{2}{*}{ Colour of first buck* } & \multicolumn{2}{|c|}{ Offspring } \\
\hline & First mating & Second mating & & Colour* & Number \\
\hline 19 & 10 & 10 & $-\dagger$ & $\begin{array}{l}\text { B } \\
W\end{array}$ & $\begin{array}{l}3 \\
6\end{array}$ \\
\hline 20 & 8 & 8 & $-\dagger$ & $\stackrel{\text { B }}{W}$ & $\begin{array}{r}1 \\
12\end{array}$ \\
\hline 21 & 10 & $9 \frac{1}{2}$ & B & $\begin{array}{l}\mathrm{B} \\
\mathrm{W}\end{array}$ & $\begin{array}{l}1 \\
5\end{array}$ \\
\hline 22 & 10 & $9 \frac{1}{2}$ & w & $\stackrel{\text { B }}{W}$ & $\begin{array}{l}1 \\
4\end{array}$ \\
\hline 23 & 10 & 9 & B & $\stackrel{\text { B }}{W}$ & $\begin{array}{l}5 \\
4\end{array}$ \\
\hline 24 & 10 & 9 & w & $\begin{array}{l}\text { B } \\
W\end{array}$ & $\begin{array}{l}1 \\
8\end{array}$ \\
\hline 25 & 9 & 8 & B & $\stackrel{\mathrm{B}}{\mathrm{W}}$ & $\begin{array}{l}4 \\
2\end{array}$ \\
\hline 26 & 9 & 8 & W & $\begin{array}{l}\text { B } \\
W\end{array}$ & $\begin{array}{l}1 \\
8\end{array}$ \\
\hline $\begin{array}{l}27 \\
28 \\
29 \\
30 \\
31\end{array}$ & $\begin{array}{l}8 \\
8 \\
7 \\
6 \\
6\end{array}$ & $\begin{array}{l}7 \\
7 \\
6 \\
5 \\
5\end{array}$ & $\begin{array}{l}\text { B } \\
\mathbf{W} \\
\mathbf{B} \\
\stackrel{W}{ } \\
\mathbf{B}\end{array}$ & $\begin{array}{l}\mathrm{W} \\
\mathrm{W} \\
\mathrm{W} \\
\mathrm{W} \\
\mathrm{W}\end{array}$ & $\begin{array}{l}4 \\
3 \\
3 \\
8 \\
3\end{array}$ \\
\hline
\end{tabular}

* $\mathrm{B}$ is black; $\mathrm{W}$ is white.

$\uparrow$ Mated to both bucks, one immediately after the other.

they were mated. Three does did, however, conceive to a single service to the $B$ buck during this same time. Matings to a vasectomized buck as the first male at various times before ovulation did not affect subsequent fertility of a second male in the seven does so treated.

\section{DISGUSSION}

These results may be interpreted to suggest that capacitation is not an all-ornone phenomenon requiring only a certain number of hours but may be likened to a gradual maturation process that permits attachment of spermatozoa 
to the egg, penetration and fertilization. A certain minimum period, $6 \mathrm{hr}$, may be required for maturation of spermatozoa but maturation continues for at least an additional $4 \mathrm{hr}$ which imparts an advantage over other less mature spermatozoa. Adams \& Chang (1962b) have suggested that capacitation might be $10 \mathrm{hr}$ in the oviduct and $6 \mathrm{hr}$ in the uterus.

It is unlikely that spermatozoa from only the first buck were at the site of fertilization at the time of fertilization because a spermatozoan transport study by Yanagimachi \& Chang (1963) shows that 28\% (37 of 132) of rabbit eggs were fertilized when the utero-tubal junction was ligated as soon as $2 \mathrm{hr}$ after mating. It is quite likely in the present experiment that there were sufficient spermatozoa for fertilization at the site of fertilization from either the first or second buck because the interval from mating to ovulation was always $2 \mathrm{hr}$ or more. Additional evidence on transport of spermatozoa has shown that spermatozoa can be recovered from the upper third of the oviduct as soon as $3 \mathrm{hr}$ after mating (Braden, 1953; Braden \& Austin, 1954). They also showed that the number of spermatozoa in the upper oviduct increases linearly for $28 \mathrm{hr}$ after mating and that there were $80 \%$ as many spermatozoa in the upper oviducts $2 \mathrm{hr}$ before ovulation as at ovulation. Assuming equal numbers of spermatozoa from each male and no interference by the first mating on transport of spermatozoa from the second buck, the ratio of the number of spermatozoa from the first buck and second buck should be 100:80 at the site of fertilization. The ratio between offspring of the first and second bucks should also be 100:80 if fertilization is random and dependent only on the ratio of the number of spermatozoa present at fertilization. In the present study, fifteen of eighteen litters produced after a $2 \mathrm{hr}$ interval between bucks, were from the first male only and the offspring were in a ratio of $6: 1$ from the first and second male in all matings. This difference from expected ratios in the proportion of one-sire litters and the proportion of offspring between first and second bucks suggests that a factor(s) other than the ratio between numbers of spermatozoa affects the ratio of offspring. Mating first with a vasectomized buck did not in any way interefere with fertilizing ability of spermatozoa from a second mating in seven does. Therefore, the first mating act in itself did not prevent fertilization by spermatozoa from the second mating. It is not readily apparent how the individual spermatozoa from the first buck could themselves block spermatozoa from the second buck.

In a study of competitive fertilization, Beatty (1957) has shown that a $3: 1$ ratio of offspring resulted from inseminating a mixture of equal volumes of semen from two bucks. He suggested that the disparity was due to a difference in fertility between the bucks rather than a difference between numbers of spermatozoa. In a later study Beatty (1960) found a ratio of 5:1 between offspring resulting from inseminations of equal numbers of spermatozoa from two different bucks. He showed that differential embryonic mortality could not account for these differences and again ascribed the disparity to differences in viability of spermatozoa. In Beatty's work, as well as in the present experiment, most males were quite fertile when used in single matings but their spermatozoa could not compete well with others following double-mating. This difference between males suggests, as an alternative explanation, that 
certain males produce spermatozoa which are either more mature at ejaculation or can mature (capacitate) faster than spermatozoa from other males. Adams \& Chang (1962b) have also suggested this possibility.

Hammond (1934) used four different strains of rabbits in a double-mating scheme with the first buck mated at $10 \mathrm{hr}$ before ovulation and the second buck at $4 \mathrm{hr}$ before ovulation. The E-strain bucks sired all offspring when used first and $60 \%$ of the offspring when used second in competition with bucks of Cstrain. The bucks of C-strain in turn sired $97 \%$ of the offspring when used first and $45 \%$ of the offspring when used second in competition with albino-strain bucks. The bucks of E-strain, when mated to several does $1 \mathrm{hr}$ after ovulation, had $24 \%$ fertile matings and 4.2 offspring/litter while C-strain bucks had no litters when used in the same fashion. These observations give further support to the interpretation that spermatozoa from bucks of certain genetic strains are ejaculated in a more mature state or can mature more rapidly than others. These more mature spermatozoa therefore have an advantage over other spermatozoa when competing directly with them and can also fertilize eggs when late mating takes place.

In the same study, Hammond (1934) was led to postulate that the litter size following late mating was reduced due to failure of spermatozoa to reach the site of fertilization until after the eggs were no longer fertilizable. He visualized the spermatozoa were transported en masse but did not examine the oviducts or eggs to justify his notion. Adams \& Chang (1962a) showed that spermatozoa were present and fertilization did take place after late mating and so ruled out his assumptions both that spermatozoa did not reach the site of fertilization and that fertilization did not take place.

Roberts \& Dawson (1935) used double-mating in rabbits to test competitively the effect of a dietary arsenical on fertility. They found, following 216 double matings with both treated and untreated bucks, that the proportion of offspring from treated bucks was 46, 23 and $16 \%$ before, during and after treatment, respectively. Semen examination revealed no obvious cause for the reduced proportion of young from treated males. Single matings to treated males during the same time showed no reduction in fertility. It is possible that treatment may have affected the state of maturity of the spermatozoa at ejaculation or their rate of post-ejaculatory maturation. Spermatozoa from a male may compete effectively at one time but not at another while still retaining fertility in a non-competitive situation. This may account for the fact the B buck in the present experiment had no offspring from does $27,28,29,30$ and 31 when in competition with the $\mathrm{W}$ buck, but was still able to fertilize three does at the same time when mated singly.

Double or multiple mating in swine has shown that certain males sire a preponderance of one-sire litters and a preponderance of total offspring in all litters (Sumption, 1961; Roberts \& Carroll, 1939). Sumption (1961) suggested competitive fertilization following multiple matings would provide a genetic basis for selection for fertility. This may not necessarily be true if a spermatozoon fertilizes an egg in competition with other spermatozoa only because it has some temporal advantage in its state or rate of maturity at or following ejaculation. 
A differential state or rate of maturation of spermatozoa within one ejaculate might explain aberrant genetic and sex ratios noted under some conditions. An example of such a disparity in the sex ratio was reported by Hays (1918) who mated bucks twenty consecutive times at 15 min intervals. The percentage of male offspring was 56, 44, 44, 36 and 22 from matings at the 1st, 5th, 10th, 15 th and 20 th ejaculate respectively. There were seventy-six to 117 offspring sexed in each ejaculate group. A possible explanation may be that, in a population of relatively immature spermatozoa such as would likely to be produced at the 15th and 20th ejaculate, the X-bearing spermatozoa are either more mature or can mature faster than their Y-bearing competitors. Noyes et al. (1958) also suggested that some spermatozoa are capacitated sooner than others in the same ejaculate.

Maturation (capacitation) may well be a process which permits spermatozoa to attach to and penetrate the zona pellucida. Competitive fertilization studies may be a means of comparing the rapidity of spermatozoan attachment and penetration between genetically different males, between males treated differently or even possibly between spermatozoa within an ejaculate.

While most of the preceding discussion is based on studies designed usually to test other hypotheses, the interpretation of results tends to support the idea that some spermatozoa have a distinct competitive advantage because they are ejaculated in a more mature state or can mature faster than other spermatozoa.

It is concluded on the basis of the present experiment that spermatozoa that have resided in the doe for $2 \mathrm{hr}$ longer (at least up to $10 \mathrm{hr}$ total) than others have a distinct advantage in fertilizing ability. That a prolonged preovulatory residence of spermatozoa in the female would be a disadvantage is suggested by Hammond \& Asdell (1926) but confirmation of this will need additional work, preferably in species which have a long interval between the onset of heat or mating and ovulation.

\section{REFERENCES}

Adams, C. E. \& Chang, M. C. (1962a) The effect of delayed mating on fertilization in the rabbit. 7. $\exp$. Zool. 151, 155.

Adams, C. E. \& Chang, M. C. (1962b) Capacitation of rabbit spermatozoa in the fallopian tube and in the uterus. F. exp. Zool. 151, 159.

Austin, C. R. (1951) Observations on the penetration of sperm into the mammalian egg. Aust. F. sci. Res. 4, 581.

BeAtTy, R. A. (1957) A pilot experiment with heterospermic insemination in the rabbit. 7. Genet. $55,325$.

Beatty, R. A. (1960) Fertility of mixed semen from different rabbits. 7. Reprod. Fertil. 1, 52.

BRADEN, A. W. H. (1953) Distribution of sperms in the genital tract of the female rabbit after coitus. Aust. F. biol. Sci. 6, 693.

Braden, A. W. H. \& Austin, C. R. (1954) The number of sperms about the eggs in mammals and its significance for normal fertilization. Aust. F. biol. Sci. 7, 543.

Chang, M. C. (1951) Fertilizing capacity of spermatozoa deposited into the fallopian tubes. Nature, Lond. $168,697$.

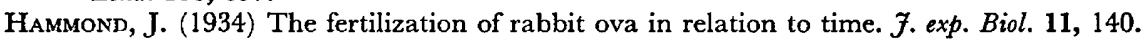

Hammond, J. \& Asdell, S. A. (1926) The vitality of spermatozoa in male and female reproductive tracts. Brit. F. exp. Biol. 4, 155.

HAys, F. (1918) The influence of excessive sexual activity of male rabbits. II. On the nature of their offspring. 7. exp. Zool. 25, 571.

Noyes, R. W., Walton, A. \& Adams, C. E. (1958) Capacitation of rabbit spermatozoa. F. Endocrin. 17,374 . 
Roberts, E. \& Carroll, W. E. (1939) A study of hybrid vigor in a cross between Poland, China and Duroc Jersey swine. F. agric. Res. 59, 847.

Roberts, E. \& Dawson, W. M. (1935) Effect of Fowler's solution on animals. Illinois agric. Expt. Sta. Bull. 413.

Sumption, L. J. (1961) Multiple sire mating in swine; evidence of natural selection for mating efficiency. F. agric. Sci. 56, 31 .

Yanagimachi, R. \& Chang, M. C. (1963) Sperm ascent through the oviduct of the hamster and rabbit in relation to the time of ovulation. F. Reprod. Fertil. 6, 413. 